\title{
ENTRE GERUNDIS I PARTICIPIS DE PRESENT EN CATALÀ MEDIEVAL
}

\author{
JORDI SUÏLS SUBIRÀ \\ Universitat de Lleida \\ suils@filcat.udl.cat
}

\section{RESUM}

En aquest article miro de fer una descripció breu del funcionament $\mathrm{i}$ la forma que presenten en català medieval, especialment en els textos del segle $\mathrm{XV}$, els anomenats gerundis i participis de present. Mostro com, en un cert període, gerundis i participis de present es confonen en alguns contextos, fins al punt que alguns lingüistes parlen de "participis gerundials". Observaré també, breument, la situació en altres llengües com l'occità, el francès i l'italià, i m'ocuparé de diversos casos particulars on algunes característiques de la temporalitat es poden explicar, al meu entendre, a partir d'una situació d'indefinició entre el caràcter verbal dels gerundis i el caràcter adjectival dels participis de present també observada per al francès actual.

PARAULES CLAU: gerundi, participi de present, català antic, llengües romàniques, temporalitat verbal.

\section{SOMEWHERE BETWEEN GERUNDS AND PRESENT PARTICIPLES IN MEDIEVAL CATALAN}

ABSTRACT

The aim of this article is a concise description of the form and the functioning shown by socalled gerunds and present participles in medieval Catalan, especially in $15^{\text {th }}$ century texts. A description is offered of how, along a certain period, gerunds and present participles merged in some contexts, to the point that some linguists have come up with the concept of "gerundial participles". I also draw some attention to the situation in other languages like Occitan, French and Italian, and I finally deal with some particularities of the verbal temporality in gerunds. Vagueness of verbal/adjectival character of medieval gerunds (as they tend to merge with present participles) might help us to find the explanatory basis for such particularities, in line with some observations regarding the case of present participles in contemporary French.

KEYWORDS: gerund, present participle, medieval Catalan, romance languages, verbal temporality.

\section{INTRODUCCIÓ}

Una característica remarcable de la llengua dels textos catalans medievals, en comparació amb l'actual, és l'elevada visibilitat de les formes de gerundi, prou sovint com a nuclis de clàusules absolutes. Fins a la darreria del segle XV, una característica associada amb l'anterior és l'existència de formes mixtes, flexionades, que per la seua forma adjectival podem considerar participis de 
present, però que en ocasions prenen una aparença a mig camí entre aquests i el gerundi. En el que segueix en faré una breu presentació. També faré atenció a dades afins que trobem en textos occitans, francesos i italians, que ajuden a posar el fenomen en una perspectiva explicativa més àmplia. I finalment exposaré evidències que, en un moment donat, les relacions de temporalitat entre el gerundi i el verb principal donen lloc a estructures innovadores. Al meu entendre, es tracta de fets de caràcter estilístic, fruit d'un moment, justament al llarg del segle XV, en què els textos es mouen a la recerca de noves possibilitats expressives. Aquesta apreciació l'hauria de validar o no una observació acurada dels textos del segle XVI en endavant. Sigui com sigui, es tracta de formes expressives que no han arribat a la llengua actual i que, en termes estructurals, interpretaré en funció de les possibilitats que manifesta el gerundi en un moment d'indefinició entre el caràcter verbal i adjectival de la qual és indicadora l'existència de formes mixtes.

En exemples com els que segueixen, el gerundi no deixa de ser una opció estilística; així, "ell vivint" de (1a), que concorre quant a context amb "mentre aquest rey visqués", de (1b). En aquest segon exemple, a més, el gerundi mostra un sentit estricte de temporalitat ("morint ell"="quan ell morís") que, en termes de llengua actual, deixa en segon terme l'aspecte duratiu que solem atribuir al gerundi:

(1) a. ... e així ell vivint ho féu jurar a sos vassals, e passà d'aquesta vida (Curial, 41).

b. hagueren per determenat que, mentre aquest rey visqués, cavalleria seria sostenguda, e, morint ell, cavalleria vendría a menys (Curial, 118).

A més a més, resultat del joc estilístic, concorren participis de present i gerundis durant un cert període, els primers en menor nombre. I com que és una opció estilística, diferents documents poden manifestar-la de manera ben diferent. Les Ordinacions de Pere III, per exemple, són un cas apart per la seua llengua extremament llatinitzant, i per contra al Tirant amb prou feines trobem algun cas de clàusula absoluta amb participi de present com la que dono a (2) (mentre que els gerundis absoluts hi són constants: podem remetre a l'exhaustiu buidatge que en fa Ferrís (1975)):

(2) ... de hon se poden recitar los naufragis de aquells qui, en ella follament navegants, a dolorosa e miserable fi pervenen (Martorell, Tirant, 806).

La coexistència entre participis de present i gerundis en els textos medievals no és un fet exclusiu de les clàusules absolutes. Té a veure amb l'assumpció per part del gerundi, possiblement ja en el llatí mateix, de valors que havien pertangut de manera exclusiva al participi de present. 
Ha estat remarcat el valor de futur, o de finalitat, que poden prendre els gerundis llatins. ${ }^{1}$ Un exemple (Valentí i Fiol 1979: 129) en seria:

(3) Caesar dando, sublevando, ignoscendo, Cato nihil largiundo gloriam adeptus est (Sal-1., Cat., 54).

'Cèsar va assolir la fama per donar, socórrer i ésser indulgent, Cató per no donar res a ningú'.

Tot i que el gerundi llatí en ablatiu, coincidint formalment amb el nostre, hauria tingut un matís interpretatiu diferent del que avui li coneixem, Lausberg (1962: 288 i ss.) hi veu ja l'anunci del ventall de lectures que ens són familiars. Segons aquesta argumentació, en veure'l com una forma més de l'infinitiu, hom pot prendre el gerundi en ablatiu ben bé per un adverbi que s'ajustaria a les funcions que aquell cas assumeix. Si l'ablatiu no preposicional presenta, entre les diverses possibles, una interpretació instrumental, llavors això és aplicable al gerundi (hominis mens discendo alitur 'la ment humana es nodreix aprenent'), i el mateix per a un ablatiu preposicional amb in, que cal entendre com a locatiu amb un matís de temporalitat (virtutes cernuntur in agendo 'les virtuts es mostren en l'acció'; adhibenda est in iocando moderatio 'cal aplicar moderació en el joc' $\approx$ 'cal ser moderats jugant'; notem com aquí divergeixen l'adjectiu verbal i el gerundi: el valor deòntic de l'adjectiu verbal adhibenda contrasta amb el del gerundi iocando que, amb la preposició in, dóna clarament una lectura locativa).

Enmig d'aquest ventall que obre el valor adverbial del gerundi, hom hi veurà dos derivades evolutives fonamentals: en primer lloc, una continuació de la funció instrumental que ara esmentàvem, i que es correspondria amb bona part dels contextos que coneixem per al gerundi actual quan apareix com a complement intern al SV (es distreien explicant-se contes); en segon lloc, com a variació secundària de la instrumental, una interpretació temporal de simultaneïtat (passejaven pel parc explicant-se contes). De la segona derivada, el gerundi hauria donat lloc a un ús vinculat al subjecte, a través d'una interpretació predicativa (el gerundi de Socrates subridendo venenum hausit ['Sòcrates, rient, es va prendre el verí'] equivaldria a un adjectiu com en Socrates laetus venenum hausit ['Sòcrates, feliç, es va prendre el verí']), de manera que el gerundi pren un valor similar al del participi de present, cosa que explicaria equivalències com la que Lausberg (1962: 291) comenta: “el participi de present ocorre en llatí equiparat sintàcticament al gerundi ${ }^{2}$ (incendium,... in edita adsurgens et rursus

\footnotetext{
${ }^{1}$ El gerundi llatí "indica alguna cosa que es pot fer, que cal que es faci o que es farà (un valor expressat en l'afix -nd-)" (Valentí i Fiol 1979: 127 i ss.). El gerundi romànic prové concretament de l'ablatiu singular de la declinació nominal de l'infinitiu llatí (per exemple, al nominatiu amare hi corresponen l'acusatiu amandum, el genitiu amandi, i el datiu-ablatiu amando).

2 Pel que fa a les relacions entre els participis de present $i$ els gerundis, Lausberg no va gaire més enllà. He pres aquest autor com a representatiu d'una visió dominant en la tradició romanística. Un dels pares d'aqueixa tradició, Meyer-Lübke (1890: 553 i ss.), havia establert que calia "tout d'abord étudier les rapports du gérondif et de l'infinitif". Probablement, en prendre el llatí com a referent, estableix a priori una distinció radical entre participi de present i gerundi i
} 
inferiora populando, anteiit remedia velocitate mali 'l'incendi,... assolint els turons i novament envaint la part baixa, va superar, per la rapidesa de la devastació, totes les mesures de socors')". ${ }^{3}$

Cal afegir-hi la semblança evident, remarcada per exemple per Moll (1952: 314), entre la terminació -nt dels participis de present $i$ la dels gerundis en algunes llengües com ara el català, l'occità, o el francès, ${ }^{4}$ cosa que, si més no en context ja romànic, hauria propiciat la confluència entre uns i altres: si el gerundi havia assumit funcions del participi de present, en termes formals el gerundi també es presta a prendre un aspecte de participi de present $i$ assumir trets de flexió, no només on en resulta coincidència formal sinó fins i tot allà on la vocal temàtica del participi de present és diferent de la del gerundi; noteu, al costat de (4a), els exemples de (4b-c), on trobem "vivints" i "partints" allà on els participis de present demanarien vivents i partents, i fins i tot, com en (4b), allà on clarament tenim una forma adjectiva assumint funció nominal:

(4) a. los quals reputam de favors ben volens prosseguidors, axí quant de la nostra senyoria fervens amadors (La reintegració de la Corona de Mallorca a la Corona d'Aragó $\mathrm{V}$, carta 200).

b. los quals, per útils proprietats e suavidat de fruyts delitosos los vivints en gran stima colen (Martorell, Tirant, 127).

c. encontinent aquelles, axí com sageta volant, partints d'aquí, van al loch hon són dampnades (Metge, Lo somni, 176).

llavors, més que analitzar-los conjuntament, considera aquest darrer al costat de l'infinitiu. Potser també hi ajuda el francès, la norma del qual prescriu taxativament la distinció formal entre participi de present i gerundi (me n'ocuparé breument més avall). Par (1923: 303) es fa ressò d'aquest punt de vista: "l'opinió d'aquest [Meyer-Lübke], que dexant apart los adjectius verbals, lo romànich heretà sols del gerundi inflexionat, li fa veure una influencia erudita llatina en les formes en flexió del antich francès. En efecte, aquest escrivía 'une mere aimant son enfant; des mères aimantz leurs enfants' (...). Segons Meyer-Lübke (...) l'única dèu pera les formes verbals fou la provinent del gerundi", amb les desinències "superposades en lo mateix francès, y no precisament en l'época de sa formació". Lausberg (1962: 287) parlarà igualment de "participialització del gerundi". No és irrellevant que els textos medievals tractin com a superposables les desinències nominals de nombre sobre les formes de gerundi. Entenc que si aquesta percepció va existir, més enllà de les consideracions morfològiques, ens hem de plantejar si és sintàcticament rellevant. Par (1923: 309), seguint a la seua manera la tradició, encunya un terme que potser precisa millor l'estat de coses: "participis gerundials". Sigui com sigui, ja veurem que potser els participis gerundials o de present medievals suggereixen alguna cosa més que la simple superposició de la morfologia adjectival sobre el gerundi.

${ }^{3}$ La cita és de Tàcit (Annales, 15, 38). Nadal i Prats (1982: 465) aporten un comentari sobre aquest mateix i altres exemples.

${ }^{4}$ En aquest punt s'escau observar que la confusió formal entre gerundis i participis es fa notar també en l'acabament -nt dels primers, més propi dels participis de present, mentre que aquests darrers assumeixen també amb prou freqüència la terminació $-n$, coherent evolutivament amb el gerundi (nd $>$ nn $>$ n). Remeto ací també al que es diu a Pérez Saldanya (1998: 194). Casanova (2002) se n'ocupa tot divergint de la proposta de Moll (1952). Val a dir que els factors estrictament formals m'interessen relativament ací. Si efectivament hi ha una confluència formal, aquesta no és anterior a un solapament funcional que ja es constata en llatí. 
No sembla, doncs, que ho puguem reduir tot a gerundis (flexionats en aquest cas), sinó que en alguna ocasió també es podria parlar de participi amb aspecte de gerundi, i llavors es fa escaient el terme "participi gerundial" de Par (vid. nota 2), tot i que aquí parlaré de "participi de present" en la majoria de casos per motius d'agilitat expositiva.

Les gramàtiques històriques, tradicionalment, s'han ocupat poc de la relació entre participis de present $i$ gerundis, i han centrat l'anàlisi a identificar les funcions semàntiques de les clàusules que contenen participis de passat $\mathrm{o}$ gerundis. Moll (1952: 312 i ss.) ho aplica especialment al cas dels gerundis; altres (Badia 1981, Duarte i Alsina 1986) es fixen més específicament en aspectes morfològics dels participis, també dels participis de present.

Al meu entendre, s'ha tendit a accentuar la qüestió de la confluència de terminacions $-n d /-n t$ i el moment en què conflueixen en l'oralitat, si és que en algun moment això es va donar. Per contra, el que m'interessa ací té a veure estrictament amb els textos. Aquests no són tant un indicador de la convivència entre participis de present i gerundis en l'oralitat com l'escenari del joc entre uns $i$ altres a la recerca del rendiment expressiu. La semblança formal que els caracteritza en català, occità i francès, lluny de representar un problema d'homofonia, licitarà l'aparició d'algunes innovacions que, però, troben els seus precedents en el llatí mateix.

Collart (1967: 76 i ss.) aporta, entenc, un bon resum sobre les relacions entre gerundi i participi de present en llatí. Aquest darrer, en bonne latinité té un ús exclusivament adjectival, i tanmateix s'apunta que els seus usos atributius ( $u t$ tu sis sciens, 'perquè en siguis sabedor') "relèvent de la langue populaire". És així que, en el baix llatí, en modificar-se les oposicions aspectuals, dictus est substitueix dicitur i dicens est apareix com a paral-lel imperfectiu de dictus est, i trobem documentats parells com legens sum/lego o legens fui/legi. D'altra banda, al costat del seu valor verbal, el participi de present pot expressar en llatí "un trait de caractère, la manière d'être et non plus le procès en cours", com en alieni appetens ('àvid dels béns d'altri').

Al costat del valor adjectival, que es va establint fins a la nominalització en baix llatí, el valor verbal del participi de present es consolida: "il exprime l'action annexe qui se déroule en sumultanéité avec l'action principale" (Collart 1967: 78), i en conseqüència, en funció del verb principal, es pot associar a qualsevol temps, però "elle peut aussi se référer à l'atemporel: currens fugit hora". I encara, com a cosa rellevant en termes de confluència cap al gerundi que veurem tot seguit, “l'absence de participe passé aidant, il peut arriver que le participe présent glisse vers une valeur passée. Le cas se produit surtout quand entre deux actions simultanées, il n'y a pas synchronisme de bout en bout: id quidem agitans, inueni remedium huic rei ['així reflexionant, vaig trobar la solució del problema', Terenci, Phormio, IV, III]; la réflexion a évidemment commencé avant la trouvaille".

Entre les equivalències que Collart (1967: 79) dóna en llatí per al participi de present, hi hauria també el gerundi (regreditur omnia temptans et circumspiciens 
['retorna, provant-ho i meditant-ho tot', Sal-lusti, Bellum Jugurthinum, 93]), que finalment s'imposarà davant del participi de present en contextos on té valor instrumental. I de fet entre els valors interpretatius que es poden donar al participi de present llatí podem trobar els que en la llengua d'avui prendria el gerundi (Collart, 1967: 80, ho exemplifica tot remetent a l'autoritat dels clàssics; n'obviem ací les referències): equivalència d'oració relativa (uideo pueros ludentes ['veig canalla jugant']); de causal (idque adeo metuens uos celaui quod nunc dicam, que Collart tradueix: "c'est justement parce que je craignais ça que je vous ai caché ce que je vais vous dire à présent"); de concessiva: at, ut oculus, sic animus, se non uidens, alia cernit ("mais, comme pour l'oeil, l'âme, quoiqu'elle ne se voie pas elle-même, distingue les autres objets"); de condicional: ...ne uno loco manens equos militares perderet ("de peur que, s'il restait au même endroit, il ne perdit les chevaux de l'armée"); de temps: ...adueniensque ilico me salutauisti ("dès que tu es arrivé, tu m'as tout de suite salué"). I, cosa rellevant en termes romànics, també equivalència d'interpretació final: uenerunt pacem petentes ['van vindre demanant pau'] (que no atribueix a cap autor i que qualifica de "peu classique", tot i que és quasi una expressió fixada); cfr. el que es dirà arran dels exemples (27) i (28). ${ }^{5}$ Indica finalment que el participi de present semblava un tret en declivi en el llatí preclàssic, però al llarg del període imperial viuria una eclosió important que es faria notar en època tardana. En el període medieval, el gerundi l'hauria desplaçat de bona part dels usos no estrictament adjectivals però, si més no per algunes llengües, hom podria constatar-ne tardanament una nova revitalització. El que s'ha dit, doncs, sembla indicar un procés de confluència entre participi de present i gerundi, a través del caràcter funcionalment genèric de l'ablatiu (confluència que licita les formes flexionades de gerundi en els nostres textos medievals). Aquest confluència s'haurà de resoldre com un procés intern, tot atribuint al gerundi el valor verbal i deixant el participi de present per als usos adjectivals. Un cas particular és el de la gramàtica prescriptiva francesa, que mirarà de clarificar l'aparent indefinició medieval tot establint que els gerundis van introduïts per en, explicitant-ne així l'ús adverbial. ${ }^{6}$

\footnotetext{
${ }^{5}$ Una consideració a fons de les relacions entre el llatí medieval i l'incipient català escrit seria fonamental en aquest punt. En una perspectiva més general, sobre l'estructura de les construccions llatines amb gerundi: cfr. Vester (1985).

${ }^{6}$ L'ús de la preposició en pròpia dels gerundis no deixa de representar una certa continuïtat, si més no en el marc indoeuropeu. Sembla que el llatí clàssic havia fet confluir en l'ablatiu altres dos casos: l'instrumental i el locatiu (Meillet 1972: 98, Bassols 1973: 117-158, Bassols 1945). El sànscrit, que conserva ambdós casos, expressa en locatiu les clàusules absolutes, tant en participi de present -(i)- com de passat -(ii)- (Goldman i Sutherland 2004):

(i) rāme vanam gacchati sarve janā duhkhitā abhavan

'Anant [loc.] Rama [loc.] al bosc, tothom va ser infeliç'.

(ii) tasminhate rākșase sarve janā bhayamuktā abhavan

'Destruït [loc.] el dimoni [loc.], tothom es va veure alliberat del temor'.
} 


\section{PARTICIPIS DE PRESENT I GERUNDIS. EL CATALÀ I ALTRES LLENGÜES ROMÀNIQUES}

Prenc en consideració especialment una descripció general sobre l'occità, el francès i l'italià, tres llengües properes al català que ens aporten informació d'interès per a esbossar finalment un marc explicatiu ampli. No cal ara remarcar, per exemple, les nombroses semblances constitutives entre català i occità; més enllà d'aqueixes semblances, en el nivell de la llengua escrita, l'occità i l'italià han pogut incidir sobre el català, bé pel fet que l'occità forneix el primer model literari, i de fet la primera llengua literària vulgar per als autors catalans medievals, bé perquè els autors itàlics aporten un model discursiu lligat a la difusió de l'humanisme al llarg del segle XV.

Val a dir que, si bé els fets relatius al francès són importants en termes comparatius i explicatius, ho són també pel fet que l'occità hi pot haver confluït tot divergint del català, de manera que ens interessen també en una perspectiva diacrònica àmplia -desitjable com a marc de treball en gramàtica històrica- que contempli conjuntament català i occità $i$, de la mateixa manera que el castellà és pres en consideració en les relacions que al llarg de la història hi anirà establint el català, el francès hi té el seu paper en relació amb l'occità.

Per a l'occità medieval, Jensen (1986: 248 i ss.) fa una descripció dels participis de present que no difereix gaire del que podríem aplicar al català, i anota la concurrència entre participi de present $(5 a)$ i gerundi $(5 b)$ :

(5) a. que totz hom, cals que sia, vas senhor defendens si deu la mort recebre (Croisade Albigeoise, 179.26).

b. ens gar velhan ens gar dormen ens gar manjan ens gar beven (H. Suchier, 85.13).

També en perífrasis construïdes amb estar / anar / ésser:

(6) a. estec sospirans (Croisade Albigeoise, 185.91).

b. estai anan e tornan en cascu del signes .i. an (Breviari d'Amor, v. 4186).

c. so qu'ieu vau deziran (Cercamon, I 10).

d. d'una ren suy meravilhans (Marcabru, XXXIV 8).

D'altra banda, fora dels casos en què la funció és clarament adjectiva i la concordança amb el nom és indicadora que ens trobem davant de participis de present, Jensen parla de "gerund/participle", atès que no sempre és clar si es tracta d'un o altre. Hi ha casos clars de gerundis flexionats ("inflected gerunds") del tipus:

(7) mas Esteves traís en aucizens (P. Cardenal, XXVII 12).

On la presència de la preposició en com a introductor no convida a pensar que ens trobem davant d'un participi de present sinó d'un gerundi i, d'altra banda, són casos que il·lustren el grau de confluència entre uns i altres. 
El gerundi, en l'occità medieval, pot anar o no introduït per en: en chantan vo apel / e si, dizen al, lo vol seguir. ${ }^{7}$ En un i altre cas, "it chiefly serves to express simultaneity with the action of the main verb" (Jensen 1986: 251), amb fórmules que ens són familiars:

(8) a. et estan en preison, et el fetz moutas bonas canssos (Vidas, XV, A 10).

b. aisi leis aman, Rambautz mori (Vidas, LXXXIII, 34).

L'inventari de funcions possibles del gerundi en occità medieval es presenta en gran part coincident amb el que trobaríem en català, com ara mitjà (9a), causa o condició (9b), manera en la qual es desenvolupa l'acció (9c):

(9) a. sai perden gazanhar (P. Vidal, XXVIII, 17).

b. temen Dieu, creyssera sa ricors (G. de Montanhagol, XIII, 43).

c. e.l coms Richartz lo receup perdonan li e baisan lo (Vidas, XVII, J 24).

Com en català, "it is not uncommon for the connotations present in the gerund to be complex in nature. Thus, some of the examples (...), in addition to simultaneity, also bring information about manner" (Jensen 1986: 252).

Alibèrt (1976: 300) dóna algunes indicacions sobre l'ús del gerundi i del participi de present en occità actual, atenent també a alguns detalls sobre la llengua medieval: "l'anciana lenga usava del participi [present] coma lo francés, mentre que la lenga parlada modèrna l'ignòra completament en fòra de formas substantivadas o adjectivas e d'expressions fossilizadas coma: agulha-cosent, aiga-corrent, aiga partent del potz, de la fenèstra estant, etc." Ara bé, "per imitacion del francés o per arcaïsme, los escrivans utilizan lo participi present", i alguns exemples en serien:

(10) a. A travèrs prats anàvem florejant

b. Se n'anava, totjorn pè descauç, se cauçant res que per passar dins los endreits, vestit de la rauba blanca, cantant lo Vene Creator...

I tot seguit adverteix que "lo restabliment del participi present dins la lenga literària nos sembla bon e util, mas non deu èsser emplegat qu'amb moderacion, si l'òm vòl escriure una lenga naturala, servant la sabor del terrador." L'advertiment té a veure amb el fet que Alibèrt percep en els participis de present un gir retòric d'influència francesa. Val a dir que els casos que aporta com a exemples són participis de present sota l'òptica francesa, que és ben diferent de la que apliquem al català; el nostre participi de present, en la llengua actual, seria allò que Alibèrt anomena adjectiu verbal (també dins de l'òptica que s'aplica al francès): "lo participi present emplegat coma adjectiu verbal vària coma

\footnotetext{
${ }^{7}$ En el català medieval trobem també gerundis introduïts amb en, però de ben segur no hi són $\tan$ freqüents com en occità:

(i) e en durment, promès a justícia que si li ajudava, que el pagès no·l auciés, jamés no li faria falliment e ultratge (Llull, Meravelles III: 128).
} 
l'adjectiu: amètlas amargantas, agulhas-cosents, n'èra morenta, son de sofrents." Per contra, "a títol verbal, lo participi es invariable" com en:

(11) a. ve aquela oliveda ombrejant nòstra tèsta

b. d'ausèls pausats, d'ausèls en vòl / cantant a plec de gargalhòl

Igual que en el cas del gerundi:

(12) a. totas bèstias van beure, en dralhant los glaujòls

b. l'aiga raja en bulint dins los uèlhs dels taupàs

I observa: “dins la vièlha lenga, lo participi present aviá qu'una sola forma pel masculin e pel femenin, mas variava en nombre. Ex.: Pensants coronar un òme de cervèla, / bailèron la corona a una domaisèla (Galhard)."

En essència, el que suggereixen aquestes dades és que l'occità medieval presentava nombrosos punts de semblança amb el català pel que fa a l'ús i la coexistència del gerundi i del participi de present. Alibèrt dóna per bo allò que distingeix participis de present de gerundis en francès, i que aplica a l'occità, com ara la coreferència entre el subjecte de la clàusula subordinada i el de la principal, obligatòria en gerundis i no en participis de present, o el fet que els gerundis vagin introduïts per en mentre que, en absència d'aquesta preposició com a introductor, s'interpreti que el que tenim són participis de present.

Així doncs, Alibèrt, malgrat que adverteix contra un excessiu calc del francès, de fet es basa en el contrast gerundi/participi de present d'aquesta llengua. Aparentment, el que s'ha esdevingut és que, partint d'un funcionament molt semblant en la llengua medieval, català i occità han divergit i aquest segon s'ha ajustat al funcionament del gerundi francès. Moignet (1973: 201 i ss.) tracta de la forma medieval en -ant, "dont il est malaisé de dire quand elle est en emploi de "participe présent" et quand elle est un "gérondif"". Tanmateix, hi observem marques de concordança, com en (13b), que denoten la presència diferenciada de participis de present:

(13) a. et Lancelot le nos a hui fait entendant (Queste, 11.5).

b. Lancelos fust rois tenanz terre,... (Mort Artu, 106.13).

Pel que sembla, el francès hauria tendit a reduir aquest contrast a una sola forma invariable quan no tenia una clara funció adjectival. Es tracta llavors, tot i que Moignet no ho explicita, de gerundis, que poden anar introduïts o no per en:

(14) a. Si s'entrecomandent a Dieu molt tendrement plorant (Queste, 25.25).

b. Boort s'em parti et chevaucha par mi la forest, pensant a ce qu'il avoit veü en dormant (Queste, 174.30). ${ }^{8}$

\footnotetext{
8 Stimming (1886) i Halmøy (2003) per a una descripció del gerundi en el francès del segle XV. També és interessant Montesquieu (1832: 400 i ss.) com a gramàtica contrastiva francès-italià (és una gramàtica francesa per a italians), especialment per a les observacions sobre gerundis.
} 
El francès modern, a partir del segle XVII, reordena els usos de participi de present i de gerundi, tot introduint-hi la ja coneguda distinció entre ús adjectival, ús com a participi de present pròpiament, i ús com a gerundi; això d'acord amb les denominacions que podem trobar en la pròpia tradició gramatical francesa (Grevisse 1993: 1313 i ss.). L'ús adjectival (15a) es caracteritza per presentar concordança amb el SN adjacent i no dur selecció argumental de tipus verbal (prenem exemples de la mateixa exemplificació que aporta Grevisse 1993); el participi de present (15b), per contra, no manifesta concordança i té un comportament verbal; bàsicament, el gerundi (15c) presenta la mateixa forma que l'anterior, però va introduït per en: ${ }^{9}$

(15) a. la terre était riante et dans sa fleur première

b. imaginez Diane parcourant les forêts ou battant les halliers

c. en débarquant, je l'avais déjà remarqué

L'ús normatiu estableix que el gerundi modifica el predicat en conjunt (o el verb principal, en una formulació simple), mentre que el participi de present modifica un nom (que pot no ser el subjecte) tot mantenint també un ús verbal. Si hom observa els exemples de més amunt de seguida es conclou que la diferència entre gerundi i participi de present en francès, si hom deixés de banda la presència o absència d'introductor preposicional, no resulta gens nítida.

Es podria dir que en realitat participi de present i gerundi francesos són variants del gerundi que podem trobar en català. Però el francès normatiu n'acota els contextos: demana que el gerundi no preposicional (el participi de present) es vinculi a un nom de l'oració principal, i quant al gerundi preposicional fixa, justament a través de la preposició, les interpretacions, en favor d'un valor instrumental o temporal, de simultaneïtat amb el temps de referència.

No podem deixar de constatar el que suggereix aquesta descripció al costat del que vèiem en occità: la confluència amb el francès fa divergir l'occità del català. Més endavant haurem de tornar als fets que descrivim per al francès i ens adonarem que, tot i que la pretesa rigidesa en la distribució de participis de present i gerundis ens pot fer pensar el contrari, la temporalitat implícita en els participis de present francesos ens pot ajudar a entendre millor alguns fets del català medieval.

Havent vist que, efectivament, l'apropiació per part del gerundi d'usos corresponents al participi de present és un fet ja constatable en els textos llatins, i que aquest és el camí que segueixen les llengües romàniques tal com les coneixem avui, és oportú qüestionar-se fins on cal donar per certa la coexistència entre gerundi i participi gerundial o de present que testimonien els nostres textos medievals. D'entrada, es tracta d'una opció estilística que determinats autors

\footnotetext{
${ }^{9}$ El mateix Grevisse anota que en francès el gerundi s'havia utilitzat sense anar introduït per en, i ho exemplifica:

(i) il est cru s'abaisser servant un Medecin
} 
tenen molt present i empren assíduament, és a dir que no pot ser tinguda per marginal en una descripció que contempli la llengua en tots els seus registres; d'altra banda, hom hi ha vist una pràctica pròpia d'autors amb tendència llatinitzant o italianitzant. En aquest sentit va el que expressen Nadal i Prats (1982: 465 i seg.), que atribueixen la presència dels participis de present a "una influència erudita sobre la llengua literària, ja que la llengua viva desconeix totalment aquest ús (...). Quan Bernat Metge i els seus companys de la Cancelleria renoven aquesta forma i aquesta funció verbal del participi de present s'inscriuen en un context lingüístic que marquen, entre altres, els grans autors italians contemporanis". L'italià, doncs, hauria tingut un paper gens secundari en la configuració del català escrit, en la mesura que l'activitat cancelleresca en l'àmbit administratiu, i singularment l'aportació d'un autor com Metge en l'àmbit literari, van tindre algun impacte lingüístic. Nadal i Prats (1982) remeten en aquest punt al que diu Rohlfs (1954: 112 i ss.), que atribueix els participis de present usats "in funzione di verbo" a la llengua literària de manera exclusiva, i afirma tot seguit que "ancor più raro, e non meno letterario, è l'uso del participio in luogo d'una proposizione secondaria indipendente dalla principale". En dóna exemples de la llengua antiga, com ara:

(16) a. quando, sopravegnente la notte,... con essa insieme surse un tempo fierissimo (Boccaccio, Decamerone, 5, 1).

b. vivente il re non scoperse... (Boccaccio, Decamerone, 3, 2).

c. un libro qu'io intendo di fare Dio concedente (Dante, Convivio, 1.5.9-11). ${ }^{10}$

Per contra, en relació amb el gerundi, Rohlfs (1969: 107 i ss.) afirma que "è normalmente adoperato, in funzione d'apposizione, a sostituire il participio presente, poco usato in italiano". Es refereix al gerundi utilitzat com a complement del nom, és a dir assumint funcions d'adjectiu pròpies del participi de present, ja sigui referit, diu, al subjecte o a l'objecte:

(17) a. ed ecco il veglio onesto gridando (Dante, Divina com., "Purgatorio", 2, 120).

b. spendo il mio tempo lagrimando (Petrarca, Canzionere, 216).

c. quivi trovarono i giovani giuocando (Boccacio, Decamerone, 10, 6).

Allò que Rohlfs troba en italià antic, especialment pel que fa a la presència de clàusules absolutes amb participis de present, té semblances amb el que podem trobar en el català que hi és contemporani, i no deixa de ser remarcable que ho observem en ple desenvolupament, per als nostres textos, en autors als quals hom ha atribuït una influència d'arrel itàlica. Tanmateix, alguna diferència hem de remarcar: els participis de present, tot i que com Rohlfs indica són visibles

10 Construccions com Dio permettente (Petrarca, Rime, "Trionfo della divinità") i altres de semblants són prou freqüents, pel que sembla, en italià antic. Fórmules d'aquest estil són també freqüents en català medieval. 
en l'italià medieval, també semblen haver-hi tingut una existència més aviat esquifida. En aquest sentit van les indicacions d'Egerland (2010a: 898): l'italià va resoldre en favor del gerundi la confluència entre aquest i el participi de present i no hi hauria hagut gaire lloc a solapaments allà on el funcionament era de caràcter clarament verbal (no nominal ni adjectival); els casos que hi farien excepció respondrien a un resultat de tipus nord-italià ("forme gerundive settentrionali o gallo-romanze"), on les terminacions de gerundi i de participi de present conflueixen, que és reinterpretat en transcripcions o adaptacions toscanes: -ent/-ant>-ente/-ante (on s'esborra la distinció -ente/-endo i -ante/-ando). Notem que el que observa Egerland emmarca el toscà en una situació similar a la del castellà: el castellà medieval no sembla haver conegut l'extensió que en el català o l'occità mostren els participis de present, o gerundis flexionats. En això segurament hi té a veure el fet que no hi conflueixin les formes llatines en -ndo i en -nte. És la mateixa observació que fem per a l'italià.

La poca presència de participis de present en italià antic, en comparació amb les altres tres llengües que hem observat, fa pensar que la llarga convivència entre aquells i els gerundis, i fins i tot la hibridació entre uns i altres, que trobem en català, occità i francès és resultat del poc contrast formal que els separa. Ara bé, cal tindre en compte que la diferència entre participis de present i gerundis té també a veure amb el valor adjectival o verbal i, de retruc, amb la temporalitat que denoten en relació amb la del verb principal. Tal com veurem, de la mateixa manera que hi ha una confluència formal entre participi de present i gerundi, la temporalitat d'aquest es pot eixamplar tot seguint les possibilitats que obre aquell. Això explicaria algunes característiques de l'anomenat participi de present del francès, i també alguns fenòmens particulars del català antic, com ara els que anomeno gerundis coordinats i gerundis deslligats.

\section{GERUNDIS COORDINATS I GERUNDIS DESLLIGATS}

Sota aquest títol miraré d'explicar ordenadament diversos tipus de construccions amb gerundi que manifesten parallelismes, en un cas, amb les oracions coordinades o fins i tot completament independents, i en un altre amb sintagmes adjectius; al meu entendre, al darrere d'aquests dos tipus hi ha els dos extrems d'un funcionament de caràcter verbal i de caràcter adjectival. La poca freqüència d'aparició d'aquests tipus de construccions impedeix de fer-ne una veritable classificació, tot i que hi podem distingir casos on hi ha conjunció copulativa d'altres on no hi ha cap conjunció. Quan hi ha coordinació, doncs, parlaré de gerundis coordinats, i quan les clàusules es presentin com a independents sense ni tan sols la presència de conjunció parlaré de gerundis deslligats. D’altra banda, atès que algun dels casos que veurem ha estat objecte d'atenció a propòsit dels anomenats gerundis de posterioritat, també aquí hi dedicaré algunes observacions particulars. 


\subsection{Gerundis coordinats}

La possibilitat és doble en els gerundis coordinats; la clàusula de gerundi pot adoptar l'aparença d'una oració simple a la qual se'n pot coordinar una altra, que la segueix, amb un verb flexionat, com en (18):

(18) a. e cerquant trobí companyia assau útil a las mies pacions. Ab la qual trobant-me e en delitosa part amaguant-me, segons la nostra entigua usansa, e primerament comensam a reonar ab orda assau discret (Corbatxo, 14).

b. D'ell a mi passaren moltes rahons qui seria aquell qui primer se recolliria. Ell tenint vot fet e yo no volguí veure los majors perills que en les armes poden ésser, ab la gran multitut de moros que y havia (Martorell, Tirant, 453).

Els podem interpretar com a casos de conjunció expletiva: l'absència de conjunció $e$, de fet, facilita la interpretació del conjunt sota una lectura en termes de llengua actual.

En altres casos, a la inversa, és l'oració amb gerundi que es coordina en segona posició. En aquest cas l'aspecte no és tant el d'una oració completament independent, sinó que és admissible, tot i que amb un cert esforç interpretatiu per a nosaltres, entendre que el gerundi aporta el valor circumstancial propi d'un adjunt, tot remarcant-ne el caràcter d'addenda o de continuïtat en una descripció. En un exemple com (19) ho podem observar comparadament:

(19) se ajuntaren a la Seu les confraries de la ciutat ab tota lur luminària ý tots los pelegrins qui havien anar en la pelegrinació. Ý, partint de la Seu ab tot lo clero, anant primer los minyons ý minyones, molt ordenats ab hun crucifix devant (Dietaris de la Generalitat de Catalunya (2/2), 420b).

La clàusula de "partint" és un adjunt dins d'una altra oració amb gerundi, construïda sobre "anant"; aquesta darrera es pot interpretar com a coordinada amb la principal que té com a verb "ajuntaren".

Als gerundis de (19) els podem atorgar un valor temporal de posterioritat (lògicament, les confraries parteixen de la Seu després que s'hi hagin ajuntat). A (20) ens trobem un cas encara més remarcable en aquest sentit (hi tornarem a fer referència més endavant, a propòsit dels exemples de (27)):

(20) E aprés de les orelles tallades, li ligaren lo picher al coll e açotant-lo entorn del camp (Martorell, Tirant, 1139).

Val a dir, també, que aquest darrer és un exemple molt més reculat en el temps que en fa un cas encara més sorprenents, atès que gerundis tan explícitament de posterioritat com el de (19) responen a un període més aviat tardà.

Els exemples de (21), que són també coordinats, responen a un esquema diferent dels anteriors, i els podem considerar estructures amb elisió:

(21) a. Guard a si mateix d'alegrar-se massa, e sobremanera guardant les ocupacions immortals del regiment de son regne (Martorell, Tirant, 607). 
b. començà Ffiameta, a la qual tocava la volta del novel-lar, e tornant-li a memòria una novel-la qui no gayre de menys perill era stada que la damunt dita de Laureta (Decameró, 107).

La conjunció que enllaça el gerundi simplement n'emfasitza el contingut, la qual cosa deriva del fet que es busca el paral-lelisme entre tots dos membres de la coordinació, amb elisió del verb principal (i part dels seus arguments) en el segon, a l'estil de les estructures de buidatge (Brucart 1984).

L'ús de la puntuació afavoreix la idea que el gerundi es troba separat del discurs precedent, més encara quan la separació és mitjançant un punt. Tanmateix, la puntuació és un element relatiu a la presentació formal del text, no pas necessàriament a les relacions estructurals entre els seus components. La feixuguesa del discurs, per exemple, pot demanar la inserció d'una pausa que separi la clàusula de gerundi; és així que a (22) ens trobem amb casos homologables amb (21):

(22) vos hé fet venir en tal dia perquè la necessitat ho requir per manifestar-vos la dolor inextimable que la mia ànima sent, (...). E no donant-vos més spay sinó fins a demà, que-1 sermó sia acabat, que tota la vostra religió serà perduda (Martorell, Tirant, 365).

\subsection{Gerundis deslligats i gerundis de posterioritat}

Els exemples anteriors mostren una certa paradoxa en el fet que un gerundi es vegi parcialment deslligat de l'acció principal anant-hi inserit mitjançant una conjunció copulativa, i la raó és que, precisament per anar inserits amb conjunció, aquells gerundis s'acosten al paper que faria un verb flexionat independent.

En altres contextos ens trobem clàusules amb gerundi que, tot $i$ anar inserides com esperaríem, sense cap conjunció, es distancien també de l'acció del verb principal. En algun cas com els de (23) podem entendre que el gerundi és equiparable a un infinitiu; així "visitant" per "visitar" a (23a), que s'afegiria als infinitius precedents "mirar, besar e adorar" però que segurament es veu afavorit per l'adjunt "aconsolant-me ab aquelles"; o "venint", que clarament equival a "venir" a (23b):

(23) a. Los engans que a la ma pensa fins ara han detengut són stats mirar, besar e adorar algunes joyes e coses que vostres són stades, aconsolant-me ab aquelles. Aprés, visitant les portes de la mia habitació, dient: “Açí seÿa lo meu Tirant. Açí reposava. Açí:m pregué. Ací·m besà. Açí, en aquest lit, me tingué nua". E axí, discorrent gran part de la nit e del dia remeyava part de mos acostumats treballs (...) (Martorell, Tirant, 1332).

b. Donchs, venint contra Déu és renegar-lo (Martorell, Tirant, 837).

Tanmateix, aquesta equivalència amb l'infinitiu no sempre ens pot servir per a entendre l'existència de gerundis deslligats. A l'exemple (24a), "trobant" podria lligar-se lògicament al discurs precedent, a manera de conseqüència (i remarquem que ho fa després d'un punt i apart). I, no amb valor consecutiu, però 
sí seguint un lligam lògic en els esdeveniments, podem entendre un exemple com $(24 b)$ :

(24) a. Cosa és perfeta les reglas de virtut del príncep prosseir hí en ell ésser mirades, qui és la font de la qual los freturans de tal mester prènan aygua.

Trobant dos virtuts per les quals les gents són honrades: huna prenent de part de la ànima, altra del cos (Turell, Arbre d'honor, 91).

b. E donà fi en son parlar.

Acabant Tirant les sues gracioses paraules, quant Plaerdemavida se lançà davant los seus peus per voler-los-hi besar. E Tirant no u comportà..., (Martorell, Tiran, 1302).

Es pot entendre aquí que som davant d'un recurs discursiu, a manera de represa argumentativa. Clarament però, especialment en el segon cas, es pot parlar de gerundi deslligat sintàcticament, com a equivalent a una oració amb verb flexionat, més quan s'hi subordina una altra oració introduïda per "quant". ${ }^{11}$

Tanmateix, els gerundis de (24) mantenen la referència a un SN precedent: a (24a) "los freturans"; a (24b) "Tirant", que, tot i que és patent dins de la clàusula absoluta, és també el subjecte de l'acció precedent de la qual la clàusula absoluta és una paràfrasi. El caràcter deslligat del gerundi és més evident quan tenim clàusules en funció d'adjunt lliure el subjecte de les quals, que com a cas general coincidiria amb el del verb principal, pren una referència diferent. Fixem-nos en la referència del subjecte de "condamnant" a (25a), que seria "totes" en un esquema típic d'adjunt amb valor instrumental o de manera, i contrastem amb la de "demanant" en els altres dos exemples: jo, que difereix de vós en (25b), i nosaltres, que divergeix del subjecte indeterminat de "se moren" en (25c):

(25) a. E si lo contrari féu, lo que no és presumidor, reportarà la merçé vostra aquella confusió e vergonya de poch amar, e blasmada per totes les dones d'onor, e totes vos daran per pena que siau desagraduada de tota gentilesa, puix no voleu sentir la glòria que de amor se ateny, condamnant-vos que siau exellada en la ylla dels Pensaments (Martorell, Tirant, 629).

\footnotetext{
${ }^{11}$ Cal no caure en una lectura massa acostada a la llengua actual, per exemple en casos on el/la qual introdueix el subjecte sense ser un veritable relatiu. Així, es pot pensar que a l'exemple (i) cal que interpretem "lo qual dit rey Rodrigo" com "lo dit rey Rodrigo", i a l'exemple (ii) simplement podem obviar "la qual" i interpretar "venint ab mantell de pau" com a incís. D'aquesta manera, els gerundis ja no apareixen com a deslligat de l'oració principal:

(i) Ara, relexant los actes e tractes que lo compte Julià feya ab los reys serrayns de haver lo traüt, tornant al rey Rodrigo que romàs en Algezira d'Alfadre ab la muller e filla dell dit compte, lo qual dit rey Rodrigo, per complir sa voluntat mala, féu-se malalt. E la comptesa e filla (...) (Sumari d'Espanya-5, 18).

(ii) E a veritat, no pot ésser a l'hom guerra pus greu que és ab sos propis costums e coratge, car lavors hi pot haver menys treves, puix la guerra és tota dins lo mur, ço és, dins l'om mateix. E aquesta guerra flaqua de batailles acostumant, la qual venint ab mantell de pau, ha major gosar que quant ve ab bacinets armada (Martorell, Tirant, 603).
} 
b. En una part me comdamnau, en altra me dau sentència de vida, demanant a la merçé vostra que davant la il-lustríssima princessa aquella sia jutge, qual de vós o de mi demana més justa causa (Martorell, Tirant, 629).

c. Acostaren-se al benaventurat sant alguns de sos dexebles dient-li: "Reverent pare, en aquesta ciutat granment se moren, demanant-vos de gràcia que vullau partir per alguna altra terra on de tan cruel pestilència pugam ésser delliures" (Péreç, Vida de Sant Vicent Ferrer, 96).

El valor interpretatiu és el mateix en tots tres casos, però la manca de coreferència fa que els gerundis de $(25 \mathrm{~b}-\mathrm{c})$ es presentin com a deslligats. La clàusula de gerundi presenta valor aparentment consecutiu. Aplicat als casos de (25b-c): "en una part me comdamnau, en altra me dau sentència de vida, demanant (= així doncs demanam) a la merçé vostra...", o "en aquesta ciutat granment se moren, demanant-vos (= així doncs vos demanam) de gràcia que vullau partir...".

Per aquesta via es pot interpretar el gerundi "lançant-lo" i els que el segueixen a l'exemple (26):

(26) “Lo quart és, qualsevulla cavaller qui en armes se trobarà, axí en mar com en terra, no fugirà per molts enemichs que veja. Bé's pot retraure tornant atràs ab la cara davant los enemichs, no girant aquella. E si girava la cara cauria en molt leig cars de falç e de perjur, lançant-lo de la fraternitat, desagraduant-lo de tot l'orde de cavalleria, fahent un home de fust a mans, braços e peus, armant-lo de totes armes, donant-li baptisme, posant-li propi nom en la desagraduació" (Martorell, Tirant, 351).

Casos com aquest darrer han dut a plantejar seriosament la possible existència de gerundis anomenats de posterioritat en els textos medievals catalans (de los Mozos 1974, Solà 1977a-b, Garrido 1996; o Lepre 2006 -que remet a Lenz 1944-). En qualsevol cas, el que caracteritza exemples com els de (25b-c) i (26) és la juxtaposició de la clàusula sense subjecte patent ni coreferència del subjecte tàcit amb un SN de l'oració principal, i no tant una particularitat quant a interpretació temporal, que certament pot ser de posterioritat aquí si no entenem que el "cas de fals i de perjur" es produeix precisament en la humiliació pública que pateix el cavaller, i no abans.

La manca de simultaneïtat entre el gerundi i el verb principal, i la possible interpretació de posterioritat, les hem vist a (19) i (20) tant com a (25b-c) i (26). Però el fet no té una relació necessària amb el grau d'imbricació estructural d'aquelles clàusules en l'oració principal. De fet, el deslligament temporal l'observem amb més claredat en clàusules amb gerundi com a nucli i amb estructura típica d'adjunt lliure on el subjecte de la clàusula corefereix amb el del verb principal. Per a aquests casos, hom observa un matís adjectival en els gerundis que els acosta al comportament que mostren les formes concordades que anomenem participis gerundials o de present. En aquest sentit podem entendre frases com les de (27):

(27) a. E lo metge, perlongant la cura de la cama lo matí següent, muntà sobre una sagetia, anant vert la dita costa (Decameró, 355). 
b. Com Lançalot, per remediar als mals que absència li donava, en un hermitatge se apartà, passant la vida mal reposada (Gras, Tragèdia de Lançalot, 16).

Aquests dos exemples corresponen al cas típic d'un gerundi de posterioritat (el segon correspon a l'encapçalament d'un capítol), amb adjunt lliure bastit sobre un gerundi el subjecte del qual remet al subjecte de l'oració principal. Tanmateix, resulten explicables si hom els interpreta com a paral-lels no flexius de participis de present, tal com seria aplicable als gerundis de finalitat (l'exemple (27a) s'hi adequaria especialment):

(28) a. Sobre aquestes coses e altres, senyora molt alta, trametem a vostra senyoria En Pero Pérez, (...), supplicants a vós humilment sia vostra mercé aquell benignament reebre (...) (Epist. de la València Med. II (3/4), carta 55).

b. Als quals promovedors havien respost dits tractadors que ells tornarien resposta. Per ço, don Miquel Climent, (...) vingué en dit stament, tornant resposta a la dita embaixada per dits promovedors hà dits tractadors feta, dient que dits tractadors ho havien comunicat ý tractat (Corts generals de Montsó, 68).

S'escau ara remetre a l'aspecte que pren en francès el constrast entre participis de present i gerundis i que hem esbossat anteriorment. Allà, com vèiem, independentment que no mostressin flexió, hom parlava de participis de present per a referir-se a formes acabades en -ant no introduïdes per preposició en. Ja vèiem que, en anar precedits per en, els gerundis no podien tindre una referència temporal que no fos simultània, o en tot cas anterior, en relació al temps de referència. Una predicció que en derivaria fóra que els anomenats participis de present francesos manifestessin possibilitats més àmplies que els gerundis en termes de temporalitat. Høyer (2003: 29) ho explicita tot dient: “... le Ppr [participe présent] exprime la simultanéité par rapport au VR [verbe régissant], ainsi que ferait le gérondif à sa place. Et le gérondif n'exprime pas que la simultanéité, il peut aussi exprimer l'antériorité par rapport au VR: En postant la lettre ce soir, elle arrivera demain. La postériorité semble être la seule relation logique par rapport au VR qui soit réservée au Ppr.: D'abord les tu ve ouvrent le feu sur une automitrailleuse française, tuant deux de nos compatriotes (...). Dans cette phrase, le gérondif ne peut pas remplacer le Ppr." El que en deriva és una relectura d'alguns dels nostres gerundis medievals, més encara en un context de llarga convivència entre formes invariables i formes morfològicament flexives d'aquests gerundis (ja sigui que les anomenem participis de present o participis gerundials): en molts casos els podríem assignar un valor similar als participis de present que en francès acabarien per ser distingits formalment en un esforç regularitzador; i convé remarcar aquest component normativitzador, atès que de fet, en el francès medieval, el fet d'anar o no introduïts per en no sembla un indicador definitiu; de fet, per al francès actual hi ha qui veu aquí una mateixa forma que pot o no prendre en com a introductor segons els casos: remeto a l'estat de la qüestió que aporta Høyer (2003). 
Si entenem que en els casos de (27) el valor temporal del gerundi queda en un segon terme, semblantment a allò que s'esdevé en els moderns participis de present francesos, el problema dels exemples (25)-(27) (i abans amb (19) i (20)) tindria a veure només amb el grau de disponibilitat de referent per al subjecte del gerundi. És a dir que parlem de gerundis deslligats en base a aquest factor estructural independent de la interpretació en termes de temporalitat. A (25b-c), el subjecte del gerundi (jo; nosaltres) s'interpreta a partir del context, a (26) és un subjecte indeterminat del tot absent en l'oració principal, a (27) respon a un esquema típic d'adjunt lliure on el subjecte coincideix amb el del verb principal, i entre (26) i (27) interpretaríem (29), on el subjecte del gerundi s'obté a partir d'un "ell(e)s" indeterminat, i tanmateix realitzat morfològicament en "avien pres":

(29) He la monja que per simonia serà presa, encara que sia professa, sia llançada de la religió, tornant-li los dinés he lo que avien pres quant entrà a monja (Constitucions del convent de Sant Josep, 78).

A diferència del funcionament actual del gerundi francès (i occità segons la prescripció alibertina), on la marca preposicional en és sistemàtica i, doncs, implica una lectura locativa que en termes temporals no pot ser mai de posterioritat, el gerundi en català sol anar desproveït d'aqueixa marca, similarment a l'anomenat participi de present francès. De fet, hom diria que el gerundi en el català medieval sembla manifestar un funcionament similar al d'aquest participi de present, potser més encara després d'un període de convivència entre formes concordades (participis gerundials o participials) i no concordades (pròpiament gerundis). D'acord amb això explicàvem casos com els de (27), on hem suggerit que el gerundi pot mostrar si més no un matís adjectival i una certa flexibilitat quant a la interpretació de la temporalitat. Aquesta, sovint s'estableix composicionalment, ja sigui en base a la lògica de la successió d'esdeveniments, ja sigui a partir de l'explicitació mitjançant adverbis. Un exemple anàleg a (27), però amb una lectura explícita de posterioritat, el tenim en (30):

(30) Partint de allí, prengué terra en Alicant ý ab forças de armas guanyà la ciutat ý la destroí, anant aprés talant fins a Cartagena tots los camps (Ponç d'Icart, Grandeses de Tarragona, 148).

Cal observar tanmateix que, tal com comentàvem per a (19), exemples tan explícits no els trobem fàcilment si no és en textos tardans, a partir del segle XVI.

\section{CONCLUSIÓ}

En el primer apartat d'aquest article he exposat l'existència de formes de gerundi i de participi de present, o participis "gerundials", en els textos catalans medievals, especialment del segle XV. He fet atenció als orígens llatins del 
gerundi i les seues evidents connexions amb els antics participis de present, tant pel que fa a les semblances formals com, especialment, als seus valors semàntics; he volgut remarcar com els valors que han estat observats per al participi de present troben la seua continuïtat en els gerundis. Faig poca atenció a la discussió sobre la confluència formal entre participis de present i gerundis (singularment, la terminació -nt que aquests acaben adoptant), que tracto com un afer totalment secundari davant de la confluència (per no dir confusió) de valors funcionals entre uns i altres que els textos posen de manifest.

En el segon apartat he fet atenció als gerundis en els textos medievals occitans, francesos i italians. He observat que, aparentment, a partir d'un funcionament similar en català i occità antics, aquest segon hauria tendit cap a la distribució que trobem també en el francès actual, on hi ha un gerundi introduït sistemàticament per preposició, un participi de present que hi coincideix morfològicament però no va amb preposició, i un anomenat adjectiu verbal que és el continuador de l'antic participi de present flexionat. Aqueixa distinció entre un anomenat gerundi i un anomenat participi de present és una convenció i una norma que estableix el francès tardanament i que adopta la gramàtica normativa occitana. Hem vist que, etiquetes a banda, el català i l'occità manifestaven tendències semblants en els textos antics $i$, de manera gens sorprenent, el francès hauria actuat ací com un factor de divergència entre dos llengües molt properes.

El tercer apartat el dedico a observar alguns casos particulars del català medieval, on per una banda hi ha gerundis que mostren un comportament semblant a les formes verbals finites, i per una altra gerundis que donen lloc a interpretacions temporals de posterioritat.

El panorama que en queda és que, en aparença, els gerundis catalans medievals en els textos del segle XV semblen oscil-lar entre diverses opcions dins d'un ventall de valors interpretatius, i fins i tot temporals, on hi ha extrems amb caràcter verbal o amb caràcter adjectival. Aquest és el punt central de la meua argumentació: el segle XV és un moment de màxima profusió d'estructures discursives (també estructures sintàctiques), algunes de les quals no tindran continuïtat. El joc entre gerundis i participis de present és una més d'aquelles vies de recerca expressiva, amb resultats a vegades sorprenents (vid. els casos que comentem a l'apartat 3). No demano per les característiques que l'oralitat devia mostrar, al segle $\mathrm{XV}$, en aquest punt; les evidències de què parteixo remeten tan sols als usos literaris. És ben possible que les semblances formals entre gerundi i participi de present haguessin estat resoltes molt abans en la llengua parlada; ara bé, no és menys evident que els textos literaris les reprenen i en trauen profit.

Els fets que ofereix modernament el francès (i parcialment l'occità) es mouen en la línia explicativa de les possibilitats que suggerien els textos catalans del segle XV: l'existència d'un anomenat participi de present, que formalment és un gerundi no preposicional, obre la porta a usos temporals que fins i tot podem interpretar com de posterioritat. El que licita aquesta particularitat seria el fet que el participi de present té un caràcter en part adjectival. Per altra banda, el gerundi 
(en anar introduït per una preposició locativa) només admetria una interpretació temporal de simultaneïtat o de precedència immediata (tal com també estableix la normativa per al gerundi català).

Cal dir que els textos occitans són excessivament lacunars en aquest punt: no coneixem res comparable, en l'occità del segle $\mathrm{XV}$, a la narrativa catalana d'aquell mateix moment. Això no vol dir que no existeixi; potser en un futur tindrem més evidències per construir una història comparada del gerundi en occità i en català.

Les dades que he aportat suggereixen que la confluència entre gerundis $i$ participis de present és lluny de ser un simple problema formal; el solapament funcional és ja constatable en els textos llatins, i és ben segur que no es limita ni de lluny al context romànic (vid. n. 6), tot i que es fa més palès en funció de factors de fonètica evolutiva (és el cas del català, l'occità i el francès).

A partir d'una anàlisi centrada en textos dels segles XVI i posteriors, hauria de ser possible explicar quin és el trànsit que es produeix des del panorama medieval, relativament obert, fins als usos moderns, molt més delimitats. En aquesta anàlisi hi caldria comptar, per una banda, el procés de codificació que el francès aplica a gerundis i participis de present, la confluència que hi hauria fet l'occità, i la història del gerundi en castellà, amb el qual hauria confluït parcialment el català tardanament.

\section{BIBLIOGRAFIA}

FONTS

Totes les fonts es troben dins del Corpus Informatitzat del Català Antic (CICA), en el web $<$ cica.cat>. En el web es poden obtindre les dades sobre els curadors del corpus i altres precisions (com ara la data, ni que fos aproximada, de cadascun dels textos).

BOCACCIO, J. (1964), Decameron. Traducció catalana publicada segons l'únic manuscrit conegut (any 1429), Barcelona, AHR.

DURAN, E. (1984), Lluís Ponç d'Icard i el "Llibre de les grandeses de Tarragona", Barcelona, Curial.

ENSENYAT PUJOL, G. (1997), La reintegració de la corona de Mallorca a la corona d' Aragó (13431349), vol.II, apèndix documental, Mallorca, Editorial Moll.

FUSTER, Joan (ed.) (2002), Les Constitucions del convent de Sant Josep de València (segle XVI), València, Publicacions de la Universitat de València.

LLULL, R. (1931), Llibre de Meravelles, vol. I, a cura de Salvador Galmés, Barcelona, Barcino.

METGE, B. (2007), Lo somni. El sueño. Edición, traducción, introducción y notas de Julia Butiñá, Madrid, Centro de Lingüística Aplicada Atenea.

Moll, F. de B. (1935), El "Corbatxo" de Giovanni Bocaccio, traduït en català per Narcís Franch (segle XIV), a cura de F. de B. Moll, Mallorca, Edicions de l'Obra del Diccionari.

MOSSÈN GRAS (1984), Tragèdia de Lançalot, a cura de M. de Riquer, Barcelona, Quaderns Crema. 
PÉREÇ, M. (1996), La vida de sant Vicent Ferrer, a cura d'A. Ferrando Francés, València, Universitat de València / Vicent García Editores, 79-121

PuigPARDines, B. de (2000), Sumari d'Espanya (ms. Y-III-5), a cura de J. Iborra, València, Universitat de València.

Rubio VelA, A. (1998), Epistolari de la València Medieval (II), València / Barcelona, Institut Interuniversitari de Filologia Valenciana / Publicacions de l'Abadia de Montserrat.

SANS I TRAVÉ, J.M. (dir.) (2001), Dietaris de la Generalitat de Catalunya. Anys 1411 a 1539, vol. 1, a cura de Ll. Cases i Loscos, J. Fernàndez i Trabal i L. Pagarolas i Sabaté, Barcelona, Generalitat de Catalunya, 387-460.

SERRA I PUIG, E. (coord.) (2001), Corts generals de Montsó (1585), Montsó - Binèfar. Procés familiar del braç reial, a cura de J.M. Bringué i Portella, P. Gifre i Ribas, G. Marí i Brull, M. Pérez Latre, J. Pons i Alzina, Barcelona, Generalitat de Catalunya.

TURELL, G. (1992), Arbre d'honor, a cura de Cecília Burgaya, Barcelona, Barcino.

\section{REFERÈNCIES BIBLIOGRÀFIQUES}

AliBÈRT, L. (1976), Gramatica occitana segon los parlars lengadocians, Monpeller, Cente d'Estudis Occitans.

BASSOlS DE ClimENT, M. (1945), Sintaxis histórica de la lengua latina, I, Barcelona, CSIC.

BASSOLS DE CliMENT, M. (1973), Sintaxis latina, 2 vols., Madrid, CSIC.

BRUCART, J.M. (1984), “Sobre el carácter anafórico del fenómeno de vaciado", Estudis Gramaticals, 1, 27-76.

CASANOVA, E. (2002), “L'evolució del gerundi i del partitipi de present en català medieval", Estudis Baleàrics, 72/73, 195-208.

COllaRT, J. (1967), Histoire de la langue latine, París, Presses Universitaires de France [citem per la 2a edició, de 1972].

DE LOS MOZOS, S. (1974), “¿Es arabismo el gerundio “de posterioridad"?”, Revista Española de Lingüística, 4/2 (juliol-desembre), 375-90.

EGERLAND, V. (2010), "Frasi subordinate al gerundio", a Grammatica dell'italiano antico, Salvi, G. i Renzi, L. (eds.), Bolonya, Il Mulino, 903-920.

ELVIRA, J. (1996), "Construcciones de gerundio con sujeto en la prosa histórica alfonsí", a Actas del III Congreso Internacional de Historia de la Lengua Española : Salamanca, 2227 de noviembre de 1993, a Alonso González, A. (coord.), Madrid, Arco Libros, 257267.

FERRÍs, V. (1975), "Les construccions absolutes en Tirant lo Blanc”, Revista Valenciana de Filología, 7, pàg. 193-239.

GARRIDO, J. (1996), “Gerundio especificativo y de posterioridad en español: corrección y relaciones sintácticas", a Actas del III Congreso Internacional de Historia de la Lengua Española : Salamanca, 22-27 de noviembre de 1993, a Alonso González, A. (coord.), Madrid, Arco Libros, 309-324.

GOLDMAN, R.P. i SUTHERLAND GOLDMAN, S.J. (1980), Devavānīpraveśikā. An introduction to the Sanskrit language, Berkeley, University of California, Center for South Asia Studies [citem per la 4a edició, de 2004].

GrevisSE, M. (1993), Le bon usage. Grammaire française, París, Duculot.

HALMØY, O. (2003), “Les formes gérondives dans Les XV joies de mariage et autres textes du XVe siècle", Langages, 37, 149, 25-36. 
HØYER, A.-G. (2003), L'emploi du participe présent en fonction d'attribut libre et la question de la concurrence avec le gérondif, Memòria de DEA, Universitat de Bergen.

JENSEN, F. (1986), The Syntax of Medieval Occitan, Tübingen, Max Niemeyer Verlag.

LENZ, R. (1944), La oración y sus partes, Santiago de Chile, Editorial Nascimento.

LEPRE POSE, C. (2006), "El gerundio de posterioridad ¿Un proceso de cambio?”, a Actas del XXXV Simposio Internacional de la Sociedad Española de Lingüística, Villayandre, M. (ed.), León, Universidad de León, Dpto. de Filología Hispánica y Clásica, 10601085.

MEYER-LÜBKE, W. (1890), Grammaire des langues romanes, París, Welter.

MoIGnet, G. (1979), Grammaire de l'ancien français. Morphologie-Syntaxe, París, Klinksieck.

Moll, F. de B. (1952), Gramática histórica catalana, Madrid, Gredos [citem per l'edició en català, Gramàtica històrica catalana, Universitat de València, 2006; 1a ed. de 1991].

MONTESQUIEU, B. de (1832), Grammatica classica della lingua francese, con esempj tratti da' migliori autori francesi, scritta ad uso degl' i taliani, Prato, Giachetti.

NADAL, J.M. i PRATS, M. (1982), Història de la llengua catalana. Dels orígens fins al segle XV, Barcelona, edicions 62.

PAR, A. (1923), Sintaxi catalana segons los escrits en prosa de Bernat Metge (1398), Halle/Barcelona, Max Niemeyer Foment de Pietat Catalana.

PÉREZ SALDANYA, M. (1998), Del llatí al català. Morfosintaxi verbal històrica, València, Universitat de València.

ROHLFS, G. (1954), Historische Grammatik der Italienischen Sprache und ihrer Mindarten, III. Syntax und Wortbildung, Berna, A. Francke (trad. de Persichino, S., Franceschi, T. i Fancelli, M.C., Grammatica storica della lingua italiana e dei suoi dialetti, Torí, Einaudi, 1969).

SoLÀ, J. (1977), “El gerundi. Un assaig”, Anuario de Filología, 3, 517-560.

STIMMING, A. (1886), “Die Verwendung des Gerundiums und des Participium praesentis im Altfranzösischen", Zeitschrift für Romanisches Philologie, 10, 526-553.

VALENTÍ I FIOL, E. (1979), Sintaxi llatina, Barcelona, Curial [citem per la 2a edició, de 1987].

VESTER, E. (1985), "Agentless passive constructions", a Syntaxe et latin. Actes du IIme Congrès International de Linguistique Latine, Aix-en-Provence, 28-31 Mars 1983, Touratier, C. (ed.), Aix, Université de Provence.

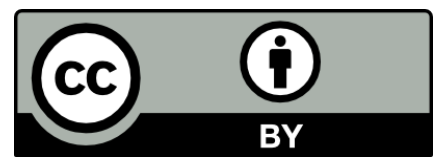

Llevat que s'hi indiqui el contrari, els continguts d'aquesta revista estan subjectes a la llicència de Creative Commons: Reconeixement 3.0 Espanya. 